\title{
Alterações da proteína $C$ reativa e fator reumatoide em cães naturalmente infectados por Leishmania spp. ${ }^{1}$
}

\author{
Paulo H. Braz ${ }^{2 *}$, Gustavo L. Lima ${ }^{3}$, Marcel C. Sartoretto ${ }^{3}$, Carolina P. Marinho ${ }^{4}$ \\ e Sandriele G. C. Deboleto ${ }^{5}$
}

\begin{abstract}
Braz P.H., Lima G.L., Sartoretto M.C., Marinho C.P. \& Deboleto S.G.C. 2018. [Changes in C-reactive protein and rheumatoid factor in dogs naturally infected by Leishmania spp.] Alterações da proteína C reativa e fator reumatoide em cães naturalmente infectados por Leishmania spp. Pesquisa Veterinária Brasileira 38(9):1829-1833. Faculdade de Medicina Veterinária, Centro Universitário da Grande Dourados, Cx. Postal 0000, Dourados, MS 79824-900, Brazil. E-mail: pauloh.braz@hotmail.com

Canine visceral leishmaniasis is a zoonosis considered a priority tropical disease. The disease affects various body systems of dogs, including viscera and skin. C-reactive protein (CRP) and rheumatoid factor (RF) are tests performed in medicine for the detection of inflammation and arthritis in humans, however, there are few studies aimed at dogs with leishmaniasis that demonstrate changes in CRP and RF. This work aimed to demonstrate the changes of $\mathrm{CRP}$ and RF and its correlation with hyperproteinemia and hyperalbuminemia, in addition to the comparison with the left deviation present in the hematological examination. The work was carried out at the Veterinary Hospital of the University Center of Grande Dourados/MS and Zoonoses Control Center, in which 34 dogs of different breeds and ages were submitted to venous blood collection for immuno-latex exams, Biochemistry and blood count in dogs naturally infected with Leishmania spp. Only dogs to the $\mathrm{DPP}^{\circledR}$ rapid test for leishmaniasis were used, together with a positive result in parasitological examination, after hematological and biochemical tests were performed. When the test for the quantification of FR in serum was performed, for the 34 animals studied, positivity was observed in only 1 animal, while the dogs were PCR positive in $38.23 \%$ of the cases studied. In cases of animals with leishmaniasis it is possible to establish inflammatory levels early, whereas the FR showed not to be a good marker for animals seropositive for the disease.
\end{abstract}

INDEX TERMS: C-reactive protein, rheumatoid factor, dogs, Leishmania spp., leishmaniasis, anemia, hyperproteinemia, arthritis, inflammation, parasitoses.

RESUMO.- A leishmaniose visceral canina é uma zoonose considerada doença tropical de prioridade. A leishmaniose afeta vários sistemas do corpo dos cães, incluindo vísceras e pele. A proteína C reativa (PCR) e o fator reumatoide (FR) são exames realizados na medicina para detecção de

\footnotetext{
${ }^{1}$ Recebido em 20 de outubro de 2017.

Aceito em 31 de outubro de 2017.

${ }^{2}$ Docente do Curso de Medicina Veterinária, Instituto Federal Farroupilha, Linha 7 de Setembro BR-386 Km 40, Centro, Frederico Westphalen, RS 98400-000, Brasil.*Autor para correspondência: pauloh.braz@hotmail.com

${ }^{3}$ Residente em Medicina Veterinária, Universidade Federal de Mato Grosso do Sul, Campo Grande, MS 79824-900, Brasil.

${ }^{4}$ Aprimoranda em Clínica Médica e Cirúrgica de Pequenos Animais, Centro Universitário da Grande Dourados, Dourados, MS 79824-900.

${ }^{5}$ Laboratório de Patologia Clínica Veterinária, Centro Universitário da Grande Dourados, Dourados, MS 79824-900.
}

inflamação e artrites em seres humanos, no entanto, há poucos trabalhos voltados para cães com leishmaniose que demonstrem as alterações ocorridas na PCR e FR. Este trabalho teve como objetivo demonstrar as alterações de PCR e FR e sua correlação com a hiperproteinemia e hiperalbuminemia, além da compararação com o desvio a esquerda presente no exame hematológico. 0 trabalho foi realizado no Hospital Veterinário do Centro Universitário da Grande Dourados/MS e Centro de Controle de Zoonoses, no qual foram avaliados 34 cães, de diversar raças e idade e submetidos a colheita de sangue venosa para realização de exames em imuno-látex, bioquímica sérica e hemograma, em cães naturalmente infectados por Leishmania spp. Foram utilizados somente cães positivos ao teste rápido DPP ${ }^{\circledR}$ para leishmaniose, juntamente com resultado positivo no exame parasitológico, depois de diagnosticados foram realizados 
exames hematológicos e bioquímicos. Quando realizado o teste para quantificação de FR em soro sanguíneo, para os 34 animais estudados, foi observado positividade em apenas 1 animal, enquanto que os cães foram positivos para a PCR em 38,23\% dos casos estudados. Em casos de animais com leishmaniose é possível estabelecer níveis inflamatórios precocemente, enquanto que o FR demonstrou não ser um bom marcador para animais soropositivos para a doença.

TERMOS DE INDEXAÇÃO: Proteína C reativa, fator reumatoide, cães, Leishmania spp., leishmaniose, anemia, hiperproteinemia, artrite, inflamação, parasitoses.

\section{INTRODUÇÃO}

A leishmaniose visceral (LV) é uma doença grave de caráter crônico e zoonótico. No Brasil, o principal agente é a Leishmania infantum chagasi. 0 cão é apontado como o principal reservatório doméstico, sendo o mais importante reservatório natural relacionado aos casos humanos (Godoy et al. 2016).

A proteína $\mathrm{C}$ reativa (PCR) é uma proteína inflamatória de fase aguda que se altera em casos de lesão tecidual. Essa proteína tem funções pró e antiinflamatórias e atualmente é um biomarcador amplamente estudado, embora, na medicina veterinária, ainda é um exame pouco utilizado na rotina clínica (Gabay \& Kushner 1999, Rosa Neto \& Carvalho 2009).

Uma das consequências da leishmaniose é o aparecimento de artrites, que afetam cerca e 19\% dos cães infectados. Diversos marcadores sorológicos vêm sendo testados como diagnósticos de artrite. 0 fator reumatoide (FR) é o que tem maior eficiência (Renaudineau et al. 2005, Soto-Blanco 2008).

Outros parâmetros que se alteram em cães com leishmaniose são os padrões hematológicos, que demonstram uma anemia do tipo normocítica e normocrômica, com leucocitose, neutropenia, linfocitose, monocitopenia e trombocitopenia. A anemia arregenerativa ocorre devido à deposição de imunocomplexos presentes no rim, que gera degeneração dos néfrons (Reis et al. 2006, Freitas et al. 2012, Braz et al. 2015).

A Organização Mundial da Saúde classifica a LV como uma das prioridades dentre as doenças tropicais devido ao aumento significativo do número de casos (Gontijo \& Melo 2004). 0 obejtivo desse trabalho foi avaliar a eficácia dos testes de PCR e FR, comparados às alterações de proteínas totais, albumina e hemograma, em cães naturalmente infectados por Leishmania spp., visto que a PCR pode ser utilizada como biomarcador para monitorar a resposta imunológica, com maior sensibilidade quando comparada a albumina e globulina (Martinez-Subiela et al. 2003).

\section{MATERIAL E MÉTODOS}

Neste estudo foram utilizados 34 cães de diversas raças, sexo e idade, provenientes do Centro de Controle de Zoonoses (CCZ, Dourados/MS), naturalmente infectados por Leishmania spp. 0 projeto recebeu aprovação do Comitê de Ética para Uso de Animais (CEUA; Parecer 01/2016).

Todos os cães que apresentaram alterações clínicas compatíveis com a leishmaniose eram encaminhados ao CCZ para realização do teste rápido $\mathrm{DPP}^{\circledR}$ Leishmaniose Visceral Canina. As principais alterações clínicas encontradas foram seborreia seca, onicogrifose, alopecia generalizada e ulcerações cutâneas.
Os cães positivos foram então submetidos à punção aspirativa com agulha fina em linfonodo para confirmação parasitológica da doença. 0 material aspirado era colocado em uma lâmina de vidro e corado em Panótico para posterior pesquisa de formas amastigota de Leishmania spp. Os animais positivos foram incluídos no projeto e submetidos a colheita de sangue venoso para a realização de exame hematológico, bioquímica sérica, FR e PCR, realizado no Laboratório de Patologia Clínica do Hospital Veterinário da Unigran, conforme descrito por Lima et al. (2014).

0 sangue venoso foi acondicionado em dois tubos, sendo um com anticoagulante do tipo EDTA-K2 para realização da análise hematológica, e outro tubo sem anticoagulante para exames bioquímicos séricos de albumina e proteínas totais.

O sangue foi processado em equipamento automático pocH-100iv e imediatamente após a leitura do equipamento foi confeccionada uma lâmina de esfregaço sanguíneo para a contagem diferencial leucocitária, análise morfológica celular e pesquisa de hemoparasitos. Nos esfregaços sanguíneos em que eram visualizados parasitos, estas amostras eram excluídas do projeto. Os exames bioquímicos séricos foram realizados em espectrofotômetro semi-automático. Os testes de albumina e proteína total foram feitos de acordo com recomendação do fabricante (GoldAnalisa ${ }^{\circledR}$ ).

Para realização dos exames de PCR foram utilizados $25 \mu \mathrm{L}$ de amostra de soro, homegeneizado com $25 \mu \mathrm{L}$ de partículas de látex revestidas com anticorpo monoclonal anti-PCR por aglutinação indireta com utilização de Kit comercial (Wama Diagnóstica ${ }^{\circledR}$ ), considerado negativo quando havia total ausência de aglutinação, indicativo de concentração inferior a $6 \mathrm{mg} /$ Litro. Quando ocorreu aglutinação do soro, a concentração era igual ou superior a $6 \mathrm{mg} /$ Litro. Quando os animais eram positivos, diluía-se o soro do paciente em salina $(\mathrm{NaCl}$ a $0,9 \%)$ nas proporções $1: 2,1: 4,1: 8,1: 16$ para semiquantificar o resultado.

Já, o FR é um teste de Imuno-Látex bastante sensível, que utiliza partículas de látex revestidas com IgG humana altamente purificada, estabilizada e suspensa em tampão glicina pH 8,2 em Kit comercial (Wama Diagnóstica ${ }^{\circledR}$ ). Foram pipetados $25 \mu$ l do soro e diluído em $25 \mu \mathrm{l}$ do reagente em cada área do cartão-teste. Foi misturado o soro com o látex, espalhando-se com uma vareta plástica. Foi observada a formação de aglutinação. 0 título da amostra correspondeu a maior diluição em que ocorreu a aglutinação

Os resultados do PCR dos cães foram comparados aos testes bioquímicos de albumina, proteínas totais e do hemograma utilizandose o teste de Exato de Fischer.

\section{RESULTADOS E DISCUSSÃO}

Ainda não há um consenso científico quando à etiopatogenia das lesões na LV. Alguns pesquisadores acreditam que a poliartrite induzida por Leishmania spp. ocorra devido à reação inflamatória granulomatosa causada pela presença de parasitos ou por uma resposta celular e humoral (McConkey et al. 2002, Reis et al. 2009), enquanto outros acreditam ser devido ao depósito de imunocomplexos circulantes na sinóvia (Cucinotta et al. 1991). A maioria das alterações radiográficas articulares de cães acometidos por LV não estão associadas à presença do parasito na sinóvia, sugerindo que a etiopatogenia das lesões articulares não é devida exclusivamente à presença do parasito (Silva et al. 2009).

Quando realizado o teste para quantificação de FR em soro sanguíneo, para os 34 animais estudados, foi observado positividade em apenas 1 animal, com valor de $8 \mathrm{mg} /$ Litro. Apesar da relação entre a positividade para o FR e o aparecimento 
da artrite reumatoide (AR) não estar elucidado, ambos estão relacionados (Goeldner et al. 2011).

A presença de agregados de imunoglobulina do tipo G (IgG) ou de complexos de IgG-FR ativa o sistema complemento e resulta em diversos fenômenos inflamatórios. A ativação do sistema complemento pelos imunocomplexos pode ainda iniciar uma inflamação vascular com depósitos de FR em arteríolas, originando vasculites (Turesson \& Matteson 2009).

A resposta inflamatória e a participação da resposta imune adaptativa nas alterações observadas em pacientes com LV é reforçada por diversas evidências, dentre elas a hiperproteinemia (Mahajan \& Marwaha 2007). A resposta humoral que se segue à infecção é caracterizada por estimulação policlonal das células B e produção de anticorpos anti-Leishmania, responsável pela hiperproteinemia em pacientes com LV (Costa-Val et al. 2007).

Dentre os animais examinados, a PCR foi positiva em 38,23\% $(\mathrm{n}=13)$. Utilizando-se o teste de Fisher para comparação entre o aumento dos neutrófilos bastonados, a hiperalbuminemia e a hiperproteinemia correlacionando com o aumento da PCR, em $\mathrm{p}<0,05$, foi possível notar que não há relação de dependência entre os testes.

A PCR tem como principal característica ser considerada uma proteína de fase aguda. Já foi demonstrada ser um bom marcador imune em estudos experimentais e em algumas doenças caninas (Eckersall 2000). Os primeiros exemplos do aumento da concentração de PCR em cães foi descrito em pacientes com leptospirose (Caspi et al. 1987), tripanossomíase (Ndung'u et al. 1991) e erliquiose (Rikihisa et al. 1994).

Os valores médios de PCR podem auxiliar na diferenciação entre cães infectados que apresentam e não apresentam sinais clínicos. No entanto, as especificidades clínicas e os valores preditivos do teste precisam ser determinados. Pode ocorrer alta taxa de animais falso-positivo no teste da PCR, devido a outras condições que são significativas para o aumento da proteína no organismo (Martínez-Subiela et al. 2002)

A hiperalbuminemia e a hiperproteinemia já foram descritas como aumentadas em cães com LV (Rosa Neto \& Carvalho 2009, Freitas et al. 2012), no entanto, o aumento da PCR é independente do aumento das proteínas, visto que a PCR tem por proposta ser um marcador precoce inflamatório. Em geral, inflamações leves e infecções virais conduzem elevações na faixa de 10 a $40 \mathrm{mg} / \mathrm{L}$, enquanto inflamações mais graves e infecção bacteriana têm concentrações séricas entre $40-200 \mathrm{mg} / \mathrm{L}$ (Aguiar et al. 2013). Desta forma, é observado que a LV tem como característica desenvolver uma inflamação leve, já que dentre os 34 cães estudados, $35,2 \%(n=12)$ apresentaram PCR variando entre 6 e $24 \mathrm{mg} /$ Litro e apenas em um caso a PCR chegou a $48 \mathrm{mg} /$ litro.

No hemograma, as alterações mais encontradas foram trombocitopenia $(82,3 \%)$, seguido de leucocitose $(82,3 \%)$, anemia $(79,4 \%)$, eosinopenia $(52,9 \%)$, neutrofilia $(29,4 \%)$, desvio a esquerda $(26,4 \%)$, monocitose $(23,5 \%)$ e linfopenia $(20,5 \%)$. Dados que corroboram os apresentados por Ikedagarcia et al. (2008), Freitas et al. (2012) e Braz et al. $(2015,2017)$. As alterações hematológicas dos cães com LV podem ser visualizadas no Quadro 1.

A hipoplaquetemia, embora tenha sido o achado mais comum, vem em desacordo com diversos autores (Reis et al. 2006, Costa-Val et al. 2007, Braz et al. 2015). A hipoplaquetemia acontece principalmente por deposição de imunocomplexos em medula óssea. Isso faz com que o animal desenvolva hipoplasia ou aplasia medular, com consequente falha na produção de plaquetas, podendo ocorrer também aumento na destruição plaquetária ou presença de imunoglobulinas anti-plaquetas (Costa-Val et al. 2007)

Neste estudo foram encontradas alterações hematológicas referentes as anemias do tipo normocítica e normocrômica. Anemia em cães naturalmente infectados com Leishmania spp. é um dos achados laboratoriais mais comuns, como relatado por Reis et al. (2006), Medeiros et al. (2008) e Braz et al. (2015), e os fatores envolvidos na sua patogênese são complexas e diversos, podendo ser relacionada com hemorragia, hemólise, inflamação, insuficiência renal, doença crónica, e aplasia ou hipoplasia medular (Koutinas et al. 1999, Krauspenhar et al. 2003).

No que diz respeito à contagem de células brancas do sangue, a leucocitose, apresentada como a segunda alteração mais comum entra em desacordo com Abranches et al. (1991)

Quadro 1. Alterações hematológicas dos 34 cães, naturalmente infectados por Leishmania spp.

\begin{tabular}{|c|c|c|c|}
\hline Índice & Média & Desvio padrão & Valores de referência* \\
\hline Leucócitos $\left(\mathrm{x} 10^{3} / \mu \mathrm{L}\right)$ & 15,48 & 9,4 & $6.000-17.000$ \\
\hline Hemácias (milhões/mm3) & 4,47 & 1,05 & $5,5-8,0$ \\
\hline Hemglobina $(\mathrm{g} / \mathrm{dL})$ & 9,42 & 2,35 & $10,0-18,0$ \\
\hline Hematocrito (\%) & 29,34 & 6,56 & $35-55$ \\
\hline $\operatorname{VCM}(\mathrm{fl})$ & 64,9 & 2,76 & $60-77$ \\
\hline CHCM (\%) & 32,5 & 2,11 & $32-36$ \\
\hline Neutrófilos (células/ $\mu$ ) & 10696,56 & 7671,1 & $3.000-11.500$ \\
\hline 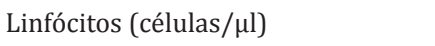 & 2499,47 & 1711,8 & $1.000-4.800$ \\
\hline Eosinófilos (células/ $\mu \mathrm{l}$ ) & 360,44 & 424,26 & $150-1.250$ \\
\hline 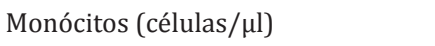 & 761,82 & 605,76 & $150-1.350$ \\
\hline Neutrófilos bastonados (células/ $\mu \mathrm{l}$ ) & 672,29 & 1627,33 & $0-300$ \\
\hline
\end{tabular}


e Ikedagarcia et al. (2008), que relatam que a leucocitose é considerada rara em cães com LV.

A linfopenia ocorrida nos cães com LV ocorre devido ao confinamento temporário esplênico dos linfócitos ou nos linfonodos, enquanto respondem ao agente infeccioso, ou até mesmo pela destruição dos linfócitos causada pelos protozoários. Os casos de eosinopenia são marcados pela falha na produção medular ou confinamento no baço (Braz et al. 2015).

\section{CONCLUSÕES}

A Proteína C reativa (PCR) é usada para estabelecer prognóstico e para monitorar a evolução de doenças infecciosas. Em casos de cães com leishmaniose é possível estabelecer níveis inflamatórios precocemente. Já o fator reumatoide (FR) demonstrou não ser um bom marcador para animais soropositivos, já que a prevalência de alteração deste exame foi pouco significativa.

Os valores hematológicos mais frequentes foram trombocitopenia e a anemia. Embora estas manifestações não sejam patognomônicas à doença, em áreas endêmicas para leishmaniose, o hemograma pode ser considerado de grande importância para a condução do diagnóstico.

\section{REFEFÊNCIAS}

Abranches P., Santos-Gomes G., Rachamim N., Campino L., Schnur L.F. \& Jaffe C.L. 1991. An experimental model for canine visceral leishmaniasis. Parasite Immunol. 13(5):537-550.<http://dx.doi.org/10.1111/j.1365-3024.1991. tb00550.x><PMid:1956700>

Aguiar F.J.B., Ferreira-Júnior A., Sales M.M.M., Cruz-Neto L.M., Fonseca L.A.M., Sumita N.M., Duarte N.J.C., Lichtenstein A.A.J.S. \& Duarte A.J.S. 2013. Proteína C reativa: aplicações clínicas e propostas para utilização racional. Revta Assoc. Méd. Bras. 59(1):85-92.

Braz P.H., Sartoretto M.C., Souza A.S. \& Melo F.M.G. 2015. Perfil hematológico de cães naturalmente infectados por Leishmania spp. Acta Vet. Bras. 9(1):87-90.

Braz P.H., Sartoretto M.C., Souza A.S. \& Siqueira M.S. 2017. Comparação entre os valores da amplitude de distribuição de diâmetro dos eritrócitos e do volume corpuscular médio com a citometria de eritrócitos em cães com leishmaniose. Pesq. Vet. Bras. 37(7):781-784. <http://dx.doi.org/10.1590/ s0100-736x2017000700020>

Caspi D., Snel F.W., Batt R.M., Bennett D., Rutteman G.R., Hartman E.G., Baltz M.L., Gruys E. \& Pepys M.B. 1987. C-reactive protein in dogs. Am. J. Vet. Res. 48(6):919-921. <PMid:3605808>

Costa-Val A.P., Cavalcanti R.R., de Figueiredo Gontijo N., Michalick M.S., Alexander B., Williams P. \& Melo M.N. 2007. Canine visceral leishmaniasis: Relationships between clinical status, humoral immune response, haematology and Lutzomyia (Lutzomyia) longipalpis infectivity. Vet. J. 174(3):636-643. <http://dx.doi.org/10.1016/j.tvjl.2006.11.006><PMid:17229582>

Cucinotta G., Iannelli N., Musicò M. \& Lombardo N. 1991. Singolare forma di Leishmaniosi: lesioni osteoarticolari bilaterali del carpo e del tarso in um cane. Praxis Vet. 12(3):12-14.

Eckersall P.D. 2000. Recent advances and future prospects for the use of acute phase proteins as markers of disease in animals. Revta Med. Vet. 151(7):577-584.

Freitas J.C.C., Nunes-Pinheiro D.C.S., Lopes-Neto B.E., Santos G.J.L., Abreu C.R.A., Braga R.R., Campos R.M. \& Oliveira L.F. 2012. Clinical and laboratory alterations in dogs naturally infected by Leishmania spp. Soc. Bras. Med. Trop. 45(1):24-29. <http://dx.doi.org/10.1590/S0037-86822012000100006> $<$ PMid:22370824>
Gabay C. \& Kushner I. 1999. Acute-phase proteins and other systemic responses to inflammation. N. Engl. J. Med. 340(6):448-454. <http://dx.doi.org/10.1056/ NEJM199902113400607><PMid:9971870>

Godoy K.C.S., Braz P.H., Assis A.R., Antunes T.R., Gomes D.C. \& Souza A.I. 2016. Avaliação dos indicadores de lesão miocárdica em cães com leishmaniose visceral. Arq. Bras. Med. Vet. Zootec. 68(2):313-320. <http://dx.doi. org/10.1590/1678-4162-8236>

Goeldner I., Skare T.L., Reason I.T.M. \& Utiyama S.R.R. 2011. Artrite reumatoide: uma visão atual. J. Bras. Patol. Med. Lab. 47(5):495-503. <http://dx.doi. org/10.1590/S1676-24442011000500002>

Gontijo C.M.F. \& Melo M.N. 2004. Leishmaniose visceral no Brasil: quadro atual, desafios e perspectivas. Revta Bras. Epidemiol. 7(3):338-349. <http://dx.doi. org/10.1590/S1415-790X2004000300011>

Ikedagarcia F.A., Ciarlini P.C., Lopes R.S., Marques F.J., Bomfim S.R.M., Lima V.M.F., Perri S.H.V. \& Marcondes M. 2008. Hematological evaluation of dogs naturally infected by Leishmania (Leishmania) chagasi submitted to treatment with meglumine antimoniate. J. Vet. Res. Anim. Sci. 45(Suppl.):68-74. <http:// dx.doi.org/10.11606/S1413-95962008000700009>

Koutinas A.F., Polizopoulou Z.S., Saridomichelakis M.N., Argyriadis D., Fytianou A. \& Plevraki K. 1999. Clinical considerations on canine visceral leishmaniasis in Greece: a retrospective study of 158 cases (1989-1996). J. Am. Anim. Hosp. Assoc. 35(5):376-383. <http://dx.doi.org/10.5326/15473317-35-5-376> <PMid:10493412>

Krauspenhar C., Fighera R.A. \& Graça D.L. 2003. Anemia hemolítica em cães associada a protozoários. Medvep, Revta Cient. Med. Vet. 1(4):273-281.

Lima M.A.M., Maia J.M., Zanetti K., Reginaldo A.S. \& Braz P.H. 2014. Comparação da sensibilidade do teste parasitológico em linfonodo, medula óssea e mucosa conjunctival para o diagnóstico de leishmaniose em cães. Acta Vet. Bras. 8(4):274-276.

Mahajan V. \& Marwaha R.K. 2007. Immune mediated hemolysis in visceral leishmaniasis. J. Trop. Pediatr. 53(4):284-286.<http://dx.doi.org/10.1093/ tropej/fmm018> <PMid:17483492>

Martínez-Subiela S., Tecles F., Eckersall P.D. \& Cerón J.J.2002. Serum concentrations of acute phase proteins in dogs with leishmaniasis. Vet. Rec. 150(8):241-244. <http://dx.doi.org/10.1136/vr.150.8.241><PMid:11916025>

Martinez-Subiela S., Tecles F., Ceron J.J. \& Eckersall P.D. 2003. Serum concentrations of acute-phase proteins in dogs with leishmaniosis during short-term treatment. Am. J. Vet. Res. 64(8):1021-1026. <http://dx.doi.org/10.2460/ ajvr.2003.64.1021><PMid:12926596>

Mcconkey S.E., López A., Shaw D. \& Calder J. 2002. Leishmanial polyarthritis in a dog. Can. Vet. J. 43(8):607-609. <PMid:12170836>

Medeiros C.M.O., Melo A.G.C., Lima A.K.F., Silva I.N.G., Oliveira L.C. \& Silva M.C. 2008. Perfil hematológico de cães com leishmaniose visceral no município de Fortaleza, Ceará. Ciênc. Anim. Bras. 18(1):43-50.

Meinkoth J.H. \& Clinkenbeard K.D. 2000. Normal hematology of the dog, p.10571063. In: Feldman B.F., Zinkel J.G. \& Jain N.C. (Eds), Schalm's Veterinary Hematology. 5th ed. Lippincott Willians and Wilkins, Philadelphia.

Ndung'u J.M., Eckersall P.D. \& Jennings F.W.1991. Elevation of the concentration of acute phase proteins in dogs infected with Trypanosoma brucei. Acta Trop. 49(2):77-86. <http://dx.doi.org/10.1016/0001-706X(91)90055-0> $<$ PMid:1680282>

Reis A.B., Martins-Filho O.A., Teixeira Carvalho A., Carvalho M.G., Mayrink W., França-Silva J.C., Giunchetti R.C., Genaro 0. \& Corrêa-Oliveira R. 2006. Parasite density and impaired biochemical/hematological status are associated with severe clinical aspects of canine visceral leishmaniasis. Res. Vet. Sci. 81(1):6875. <http://dx.doi.org/10.1016/j.rvsc.2005.09.011><PMid:16288789>

Reis A.B., Martins-Filho O.A., Teixeira-Carvalho A., Giunchetti R.C., Carneiro C.M., Mayrink W., Tafuri W.L. \& Corrêa-Oliveira R. 2009. Systemic and compartimentalized immune response in canine visceral leishmaniasis. Vet. Immunol. Immun. 128(1/3):87-95. <http://dx.doi.org/10.1016/j. vetimm.2008.10.307><PMid:19054576> 
Renaudineau Y., Jamin C., Saraux A. \& Youinou P. 2005. Rheumatoid factor on a daily basis. Autoimmunity 38(1):11-16. <http://dx.doi. org/10.1080/08916930400022574 ><PMid:15804700>

Rikihisa Y., Yamamoto S., Kwak I., Iqbal Z., Kociba G., MottJ. \& Chichanasiriwithaya W. 1994. C-reactive protein and $\alpha 1$-acid glycoprotein levels in dogs infected with Ehrlichia canis. J. Clin. Microbiol. 32(4):912-917. <PMid:8027343>

Rosa Neto N.S. \& Carvalho J.F. 2009. The use of inflammatory laboratory tests in rheumatology. Revta Bras. Reumatol. 49(4):413-430. <http://dx.doi. org/10.1590/S0482-50042009000400008>
Silva A.R.S., Vieira R.F.C., Gomes A.A.D., Aquino M.C.C., Biondo A.W., Messick J.B., Ciarlini L.D.R.P. \& Ciarlini P.C. 2009. Cytological findings in synovial fluid from positive dogs for Leishmania chagasi in an endemic area of Brazil. Vet. Clin. Pathol. 46(2):1029-1029.

Soto-Blanco B. 2008. Clinical features of canine visceral leishmaniasis at Fortaleza city, Ceara, Brazil. Arch. Vet. Sci. 13(3):218-222.

Turesson C. \& Matteson E.L. 2009. Vasculitis in rheumatoid arthritis. Curr. Opin. Rheumatol. 21(1):35-40. <http://dx.doi.org/10.1097/ BOR.0b013e32831c5303><PMid:19077716> 